\title{
Effects of Geometrical and Flow Rates on the Prediction of Bottom Pressure Coefficients of Tunnel Lift Gate of Dams
}

\author{
Sheeraz Ameen ${ }^{1}$ (D) Taha Taher $^{2} \cdot$ Thamir M. Ahmed $^{3}$
}

Received: 17 October 2016/ Accepted: 17 May 2018/Published online: 9 June 2018

(C) The Institution of Engineers (India) 2018

\begin{abstract}
Hydrostatics and hydrodynamics forces are generated and applied on the vertical lift tunnel gates due to the influence of a wide range of dam operating conditions. One of the most important forces is the uplift force resulting from the jet flow issuing below the gate. This force is based mainly upon many hydraulic and geometrical parameters. In this work, the uplift force is studied in terms of bottom pressure coefficient. The investigation is made paying particular attention on the effects of various three discharges and three gate lip angles on values of bottom pressure coefficients in addition to four different tunnel longitudinal slopes whose impact has not been studied in many previous works. Hydraulic model is constructed in this work for the sake of measuring all parameters required for estimating the bottom pressure coefficients, which are all examined against gate openings. The results show that the bottom pressure coefficient is related to the said variables, however, its behaviour and values are not necessary regular with variance of studied variables. The values are seen more significantly related to the flow rates and for some extent to the slopes of tunnel. An attempt by using the nonlinear regression of Statistical package of social sciences (SPSS) is made to set equations relating bottom pressure coefficient with gate openings for several angles of gate lips. The obtained equations are shown in good agreement with the selected cases of
\end{abstract}

Sheeraz Ameen

shirazmajid_a@yahoo.com

1 Koya Technical Institute, Erbil Polytechnic University, Erbil, Iraq

2 Istanbul, Turkey

3 Civil Engineering Department, Ishik University, Erbil, Iraq experimental results. The results are applicable for design purposes for similar geometrical and flow parameters considered in this study.

Keywords Lift gates - Bottom pressure coefficient · Down pull pressure coefficient

\section{List of symbol}

A Appropriate cross sectional area of the tunnel, $\mathrm{m}^{2}$

B Tunnel width, $m$

$b_{1}, b_{2} \quad U / S \& D / S$ gap widths between the gate \& the gate shaft

$\mathrm{C}_{\mathrm{c}} \quad$ Coefficient of contraction for the jet flow below the gate

$\mathrm{C}_{\mathrm{d}}, \mathrm{C}$ Discharge coefficients

$\mathrm{C}_{2} \quad$ Discharge coefficients for the rate of flow released over the gate

d Gate thickness, $\mathrm{m}$

$\mathrm{F}_{\mathrm{d}} \quad$ Downpull force, $\mathrm{N}$

g Gravity acceleration, $\mathrm{m}^{2} / \mathrm{sec}$

$\mathrm{H}_{\mathrm{i}} \quad$ Pressure head at a point on the gate bottom, $\mathrm{m}$

$\mathrm{H}_{\mathrm{t}} \quad$ Pressure head on the top surface of the gate, $\mathrm{m}$

$\mathrm{H}_{\mathrm{U}} \quad$ Pressure head U/S of the gate, $\mathrm{m}$

$\mathrm{H}_{\mathrm{d}} \quad$ Pressure head D/S of the gate, $\mathrm{m}$

$\mathrm{K}_{\mathrm{b}} \quad$ Bottom pressure coefficient, dimensionless

$\mathrm{K}_{\mathrm{d}} \quad$ Downpull coefficient, dimensionless

$\mathrm{K}_{\mathrm{t}} \quad$ Top pressure coefficient, dimensionless

$\mathrm{P} \quad$ Perimeter of tunnel section, $\mathrm{m}$

Q Total rate of flow, $\mathrm{m}^{3} / \mathrm{s}$

Re Reynolds number, dimensionless

$\mathrm{V}$ Average velocity, $\mathrm{m} / \mathrm{s}$

$\mathrm{V}_{\mathrm{j}} \quad$ Velocity in the contracted jet issuing from under beneath the gate, $\mathrm{m} / \mathrm{s}$

$\mathrm{X}_{\mathrm{o}} \quad$ Horizontal distance along gate bottom surface, $\mathrm{m}$ 


\begin{tabular}{|c|c|}
\hline $\mathrm{X}$ & $\begin{array}{l}\text { The horizontally distance from the leading edge of } \\
\text { gate lip toward trailin edge, } \mathrm{m}\end{array}$ \\
\hline $\mathrm{Y}$ & Height of gate opening, $\mathrm{m}$ \\
\hline $\mathrm{Y}_{\mathrm{o}}$ & Tunnel height, $\mathrm{m}$ \\
\hline $\mathrm{v}$ & Kinematic viscosity, $\mathrm{m}^{2} / \mathrm{s}$ \\
\hline$\theta$ & $\begin{array}{l}\text { Angle between horizontal and sloping bottom of } \\
\text { the gate, degree }\end{array}$ \\
\hline & Density of water, $\mathrm{kg} / \mathrm{m}^{3}$ \\
\hline & Specific weight of water, $\mathrm{N} / \mathrm{m}^{3}$ \\
\hline
\end{tabular}

\section{Introduction}

The dam tunnel lift vertical gates are mainly exposed to many hydrodynamics forces exerted by pressurized water flow in different direction. The tunnel flow stream lines almost take two paths, and accordingly the two major forces will be created. The uplift pressure force is produced by water jet flow issuing beneath the gate and caused big effects on its bottom surface and consequently on the mechanical system of gate operation. The other force is established vertically downward along the gate top surface due to the effects of water flow passing from upstream to downstream gate shaft clearances. The net force obtained from the difference of these two forces is named as downpull force which consists a very important reference for safe and economical design of gates.

The hydrodynamic forces are influenced by many main parameters that were studied by many researchers through mathematical and experimental approaches. The flow conditions and gate lip geometrics have been examined and many results were analysed and suggestions being recommended. Cox et al. proposed the dimensionless relationship of hydrodynamic force [8], which reflects the impact of aeration, geometry of gate bottom, and clearances of gate shaft on the stability of the gate. Such criterion was used in analytical approach adopted by many subsequent researches.

Naudascher et al. conducted the air tunnel tests [12] to evaluate the influences of flow conditions and geometry limits on downpull force applied to high head leaf gates. It is found that the following one-dimensional form based upon the bottom and top pressure coefficients and can be utilized for evaluating the downpul force.

$F_{d}=\left(K_{t}-K_{b}\right) \cdot B \cdot d \cdot \rho$

where $F_{d}=$ downpull force, $\mathrm{N}, \mathrm{B}=$ gate width, $\mathrm{m}$, $\mathrm{d}=$ gate thickness, $\mathrm{m}, \rho=$ water mass density, $\mathrm{Kg} / \mathrm{m}^{3}$, and $\mathrm{Vj}=$ velocity of the contracted jet issuing from underneath the gate, $\mathrm{m} / \mathrm{s}$.
$K_{t}=2 g \cdot\left(H_{t}-H_{d}\right) / V_{j}^{2}$

$K_{b}=2 g \cdot\left(H_{i}-H_{d}\right) / V_{j}^{2}$

where $H_{t}=$ Piezometric head on gate top surface, $\mathrm{m}$, $H_{d}=$ Piezometric head just downstream the gate shaft $\mathrm{m}$, $H_{i}=$ Piezometric head at a point on the gate bottom, m.

Elder presents the experimental simulation of the TVAS Melton Hill Dam 3-leaf intake gate (1964) [9] to explore the effects of gate geometries on downpull force. The study includes five suggested shapes and nine of normal shapes. The tests failed to attain the satisfactory design due to excessive hydraulic forces caused by gate lip shapes, oscillation of the gate during closure, and in many designs, leaf failure to close. The combination of lip shapes has led to an acceptable design.

The limited estimation of downpull forces were obtained from two empirical methods as suggested by Sagar [14-16], first one named, the downpull coefficient method is based on Fort Randall Dam data while the other, pressure distribution method, which is based on estimating the total forces acting on the top and bottom surfaces of the gate. These two methods are restricted to be applicable for similar gate shapes.

Bhargava [7] examined the pressure fluctuations on different geometries of vertical-lift gate. The study investigated numerous hydraulic parameters that influence the values and distributions of pressure heads for various gate openings. The intensity of pressure and its distribution pattern were studied when the gate is enforced to vibrate in the vertical direction at specific frequencies and amplitude. Total intensity of fluctuating pressures on vibrating gates was obtained by integrating the profiles of pressure fluctuations over the gate thickness. The study specifies a pressure of common frequency, which is considered as critical condition for gate design.

The unsteady loads applied for different lip geometries and flow conditions of vertical lift gate were studied by Nguyen [18]. The behaviour of the gate was examined under the effects of vibrations that had been created as results of separation and reattachment of flow streamlines beneath the gate bottom surface with specific ranges of dimensionless velocities. Such fluctuation was caused by the combined action of instable shear layer below the gate bottom and the vortices established just upstream the gate edge. The analysis leads to indicate the critical range of gate opening corresponding to potential gate vibrations (Table 1).

The one-dimensional finite element model conducted by Al-Kadi estimated the downpull force [4].This model is based upon the velocity and mean pressure distribution along the bottom gate surface. Two cases were considered, one with invariant eddy viscosity and the other with 
Table 1 Mean values of submerged flow rates and corresponding Reynolds number

\begin{tabular}{llll}
\hline $\mathrm{Q}$ & $\mathrm{Q}_{\text {Low }}\left(\mathrm{m}^{3} / \mathrm{s}\right)$ & $\mathrm{Q}_{\text {med }}\left(\mathrm{m}^{3} / \mathrm{s}\right)$ & $\mathrm{Q}_{\max }\left(\mathrm{m}^{3} / \mathrm{s}\right)$ \\
\hline Mean value & $\approx 0.028$ & $\approx 0.035$ & $\approx 0.04$ \\
Reynolds number & $1.12 \times 10^{5}$ & $1.4 \times 10^{5}$ & $1.6 \times 10^{5}$ \\
\hline
\end{tabular}

variable eddy viscosity. The model was verified with the results of analytical prediction and gave a good agreement.

Ahmed [1] investigated the effect of many gate geometries with various gate width ratios on down pull forces, the study was based on the analytical results of the measurements gained by the experimental runs conducted by using hydraulic lab model. This study concludes that the downpull coefficient is influenced by various parameters such as gate geometry and gate opening.

Experimental work on downpull force on gates installed in the intake structures of hydroelectric power plants including lip pressure distribution measurements and direct weighing of downpull was presented by Aydin et al. [6]. The downpull coefficient was defined as a function of the lip angle and gate opening. The function is combined with unsteady flow one-dimensional mathematical model, which based on the integral energy and continuity equations. The downpull force was evaluated for both cases of stationary and closing modes. The Predicted mathematical model was compared with the results obtained from the direct weighing method in order to confirm its validity.

A two-dimensional CFD model is applied by Almani et al. [5] to predict a downpull coefficient (KT and $\mathrm{KB}$ ) which is named as FLUENT program. The finite volume method is employed on a Reynolds averaged NavierStokes equations. The turbulence effects are simulated using the standard $(\mathrm{k}-\varepsilon)$ model. The simulation model was used for relevant experimental data obtained from hydraulic model tests conducted by (Ahmed 1999) in laboratory for nine gate lip shape with different gate openings for each gate lip geometry. It is found that the minimum positive downpull force can be reached for lip geometry with $\left(\theta=35^{\circ}\right)$.

The distribution of pressure around the bottom of outlet leaf gate and its potential risk of cavitation and destructive vibrations of the gates were studied by Khosrojerdi [10]. The study is based upon the three dimensional simulation of numerical method which was used to indicate the change in pressure and downpull forces during the vertical gate movements. It is found the downpull forces are influenced by the upward and downward direction of gate movements.

Naderi and Hadipour [13] examined the distribution of pressure and consequently the related hydrodynamic forces on the valve of channel outlet for many opening ratios by utilizing the numerical method based upon the finite volume principles. The numerical model was verified by the corresponding results of physical as well as previous studies where the comparison gave good agreement. The study reveals that the differences in top and bottom of the valve pressures lead to create downpull force.

Markovic-Brankovic and Drobier [11] exhibited new smooth upstream face high head gate form that reduces hydrodynamic forces in conjunction to a total (negative downpull) forces. The investigation distinguished various changes in the configuration, which would decrease downpull and by and by the expense. After various attempts, an adequate development change was found in the model. The consequences of the model tests demonstrate that an expansion in vertical openings of the gate leaf reduces the hydrodynamic forces fundamentally.

Mehmet Akiş Uysal in 2014 [19] proposed a method to predict the downpull forces on the tunnel gates which is installed in the intake of a hydropower plant. It is focusing on the evaluation of downpull forces for various closure rates and gate lip geometries. The outcomes contrasted with results, which were achieved by using ANSYS FLUENT programming as a tool for calculation. Downpull coefficients, which have been got from computational study, demonstrated great concurrence with those obtained from measurements.

Taher et al. [17] used a random hydraulic model to study the effects of twelve gate lips orientation on the behaviour of flow and consequently on the bottom pressure coefficient. The main conclusion indicates that the values of bottom pressure coefficient $\left(\mathrm{K}_{\mathrm{b}}\right)$ are inversely proportional to gate opening ratios $\left(\mathrm{Y} / \mathrm{Y}_{0}\right)$ and range from high values with small gate openings ratios and low values for ( $\mathrm{Y} /$ $\mathrm{Y}_{0}>30 \%$ ). The study finds that the bottom pressure coefficient $\left(\mathrm{K}_{\mathrm{b}}\right)$ and the fluctuations flow pattern below the gate surface $\mathrm{h}$ influenced mainly by the gate geometry.

In the current study, the down pull forces on the gates are evaluated for different flow rates, different gate lip geometries and different longitudinal slopes. The PASW Statistical Program is used for analyses and surfer program to represent the results. The measurements are carried out by using the hydraulic of tunnel model with seven different lip shapes. The Validity of the results is indicated by the comparison with corresponding cases of previous related works.

\section{Experimental Set-Up}

The experiments were conducted by using the random hydraulic model which was designed by Ahmed [3] and has been established in Hydraulic Laboratory of Ishik University/Erbil/Iraq. The model consists of a rectangular 
recirculation flume, $4 \mathrm{~m}$ long, $0.2 \mathrm{~m}$ wide and $0.3 \mathrm{~m}$ deep. The bed and both sides of channel were made by glass and covered along its upper part by a thick plate representing the tunnel roof. The steel gate shaft $(0.3 \times 0.15 \times 0.6) \mathrm{m}$ was installed mid-way above the flume roof.

The head of tunnel was fed by stilling tank to reduce the effects of turbulence. The flow is returned to the storage tank through the control sluice gate which was installed at the end tunnel. The control gate is essential to provide a pressurized status for all different flow conditions required for this study. AC motor was used to derive a $4 \mathrm{~kW}$ pump, thereby providing the discharge which was adjusted by a valve. The main measurement tools of hydraulic model are shown in Fig. 1a, b and gate details are shown in Fig. 2.

The movable bottom plates of the gate made by steel plate formed different inclined gate lip shapes. The pressure could be measured by eight piezometric holes distributed on two parallel lines along the bottom of the gate so that each line has four. First set of taps was fixed at a distance $0.25 \mathrm{~B}$ from right gate edge with equal interval distance from each to other; the second set was located with same manner at a distance $0.5 \mathrm{~B}$ from edge of gate as shown in Fig. 3. The small length steel tubes have been inserted to the taps and then connected to manometers board through plastic tubes as it can be seen in Fig. 3 .

The estimation of flow rate and the velocity distribution had been carried out by using two pito-tubes located at a distance $1 \mathrm{~m}$ upstream the gate shaft and just downstream the gate shaft respectively. Two piezometers were installed upstream the gate shaft with consecutive distances $(0.25$ and $0.5 \mathrm{~m}$ ) to measure operation heads, furthermore, another one was needed to be $20 \mathrm{~cm}$ downstream the gate shaft which is necessary for the determination of pressure coefficients. The longitudinal slope of tunnel was adjusted by using a hydraulic jack.

In current study, all relevant parameters were measured for three values of flow rates; $\left(\mathrm{Q}_{\text {Low }}, \mathrm{Q}_{\mathrm{med}}, \mathrm{Q}_{\max }\right)$. The mean values of these three flow rates had been found and consequently, the corresponding values of Reynolds number have been found by using Eq. (4) [1]. The main criteria of measurements procedure have been illustrated in Fig. 4.

$R_{e}=\frac{V \cdot d_{h}}{v}=\frac{4 V \cdot A}{P \cdot v}=\frac{4 Q}{2 \cdot\left(Y_{o}+B\right) \cdot v}$.

In above equation the $d_{h}=4 R=4 A / P$.

\section{Analysis of Mesurements}

The pertinent independent variables that affect the bottom pressure coefficient can be represented by the following functional relationship as non-dimensional terms, Ahmed [2]:

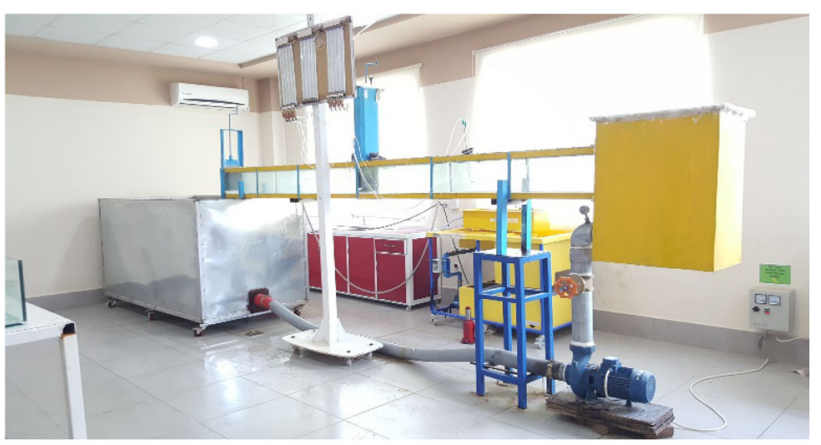

(a)

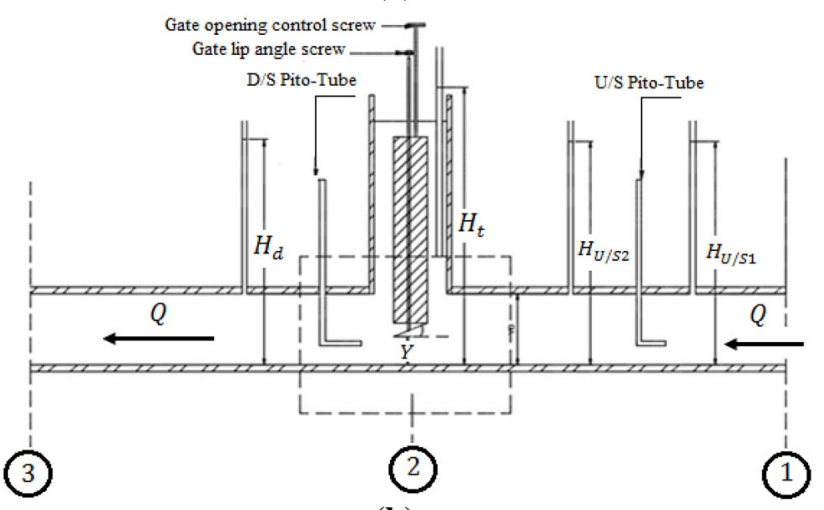

(b)

Fig. 1 a photo of hydraulic model, b schematic layout of hydraulic model

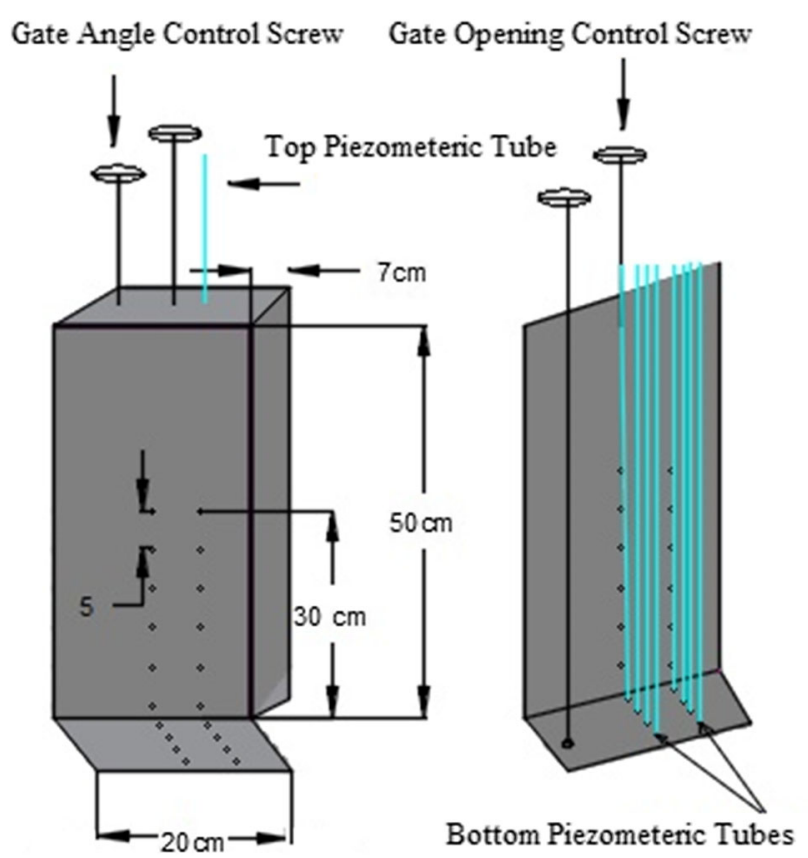

Fig. 2 Main details of gate model Ahmed et al. [3]

$K_{b}=f\left(\frac{X}{X_{\mathrm{o}}}, H_{i}, H_{d}, \frac{V_{j}^{2}}{2 g}, \frac{Y}{Y_{\mathrm{o}}}\right)$ 
Fig. 3 Piezometric holes throughout the bottom gate surface

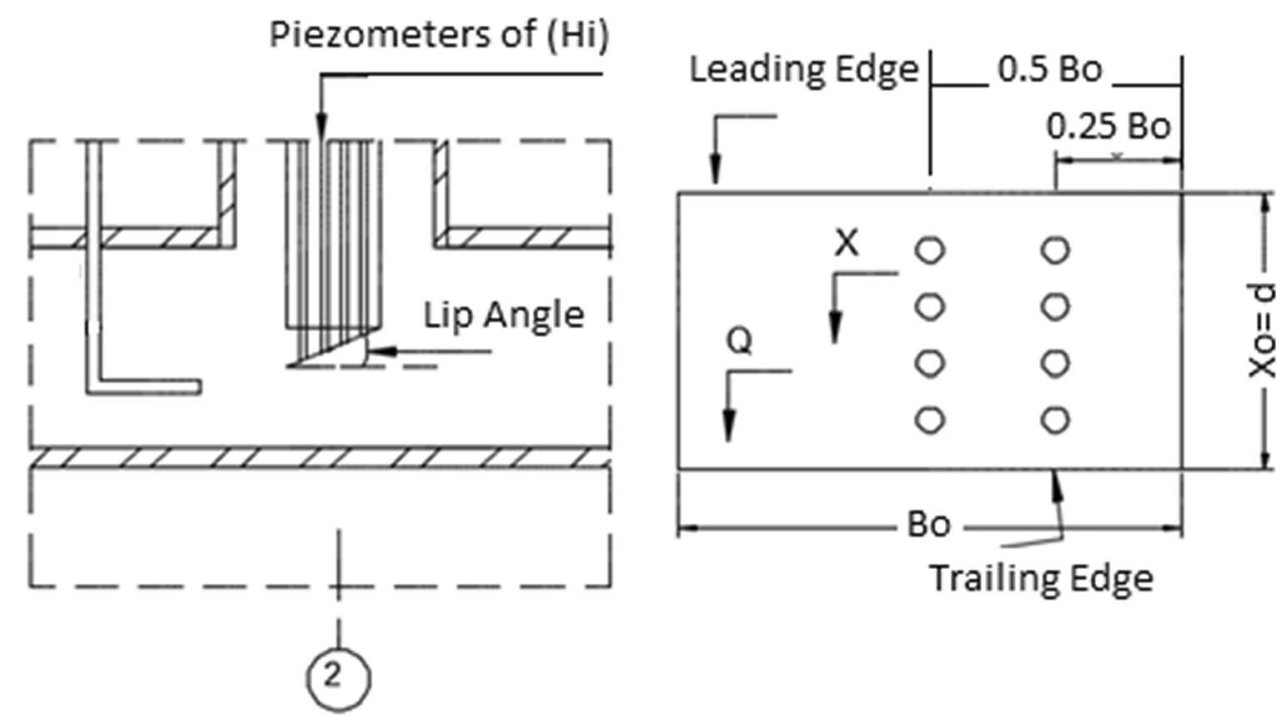

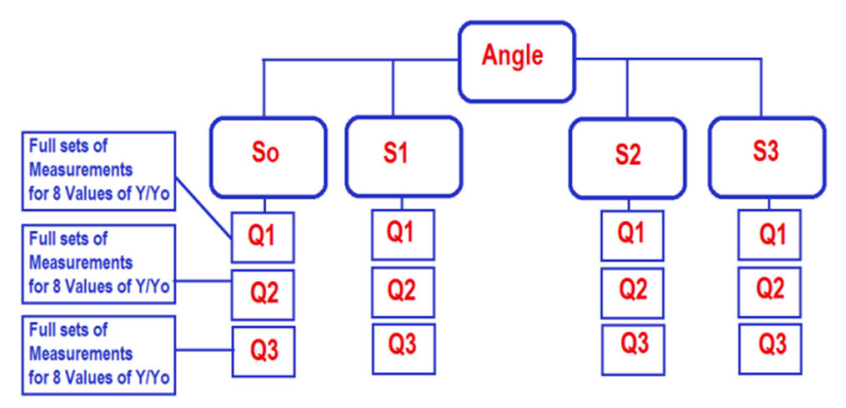

Fig. 4 Flow chart of measurements Procedure

where $K_{b}$ Bottom pressure coefficient, $\frac{X}{X_{0}}$ Distance ratio along bottom gate Surface, $\frac{Y}{Y_{0}}$ Opening ratio, $H_{i}$ Piezometric head on bottom gate surface, $\left(V_{j}^{2}\right) / 2 g$ Jet velocity head, and $H_{d}$ Piezometric head downstream gate shaft.

The bottom pressure coefficient $\left(K_{b}\right)$ is calculated using Eq. (3) in which $\left(H_{i}\right)$ is the average value of eight local piezometric heads have been measured along and across the bottom gate surface as shown in Figs. 2 and 3. The measurements were made with the gate held stationary under submerged flow conditions. In present study, effects of flow rates, gate lip geometry and longitudinal slope on $\left(\mathrm{K}_{\mathrm{b}}\right)$ are evaluated.

The variation of bottom pressure head coefficients $\left(\mathrm{K}_{\mathrm{b}}\right)$ along the different gate lip shapes of angles $\left(\theta=35^{\circ}\right.$, $\theta=37^{\circ}$ and $\theta=42^{\circ}$ ) versus various gate openings are presented in Figs. 5, 6, 7, 8, 9, 10, 11, 12, 13, 14, 15 and 16 for numerous flow rates and slopes.

Figure 5 shows the variation of $\left(\mathrm{K}_{\mathrm{b}}\right)$ values in the case of $\left(S=0, Q_{\text {Low }}\right)$. It can be seen from the figure that for small gate openings, the values of $\left(\mathrm{K}_{\mathrm{b}}\right)$ have a relatively low positive values. The increase in gate openings has led to decrease the $\left(\mathrm{K}_{\mathrm{b}}\right)$ values to be negative at approximately $\left(\mathrm{Y} / \mathrm{Y}_{\mathrm{o}}=50 \%\right)$. For gate openings more than $50 \%\left(\mathrm{~K}_{\mathrm{b}}\right)$ values are increased for all gate lip shapes and mostly the maximum values are attained for gate openings more than $70 \%$.

Figure 6 indicates that $\left(\mathrm{K}_{\mathrm{b}}\right)$ values for $\left(\mathrm{S}=0, \mathrm{Q}_{\mathrm{med}}\right)$ are decreased and being negative up to $\left(\mathrm{Y} / \mathrm{Y}_{\mathrm{o}}=60 \%\right)$ and then turned to reach the maximum positive values in the case of full gate opening. The values of $\left(\mathrm{K}_{\mathrm{b}}\right)$ for gates with lip angles $\left(\theta=35^{\circ}\right.$, and $\left.\theta=42^{\circ}\right)$ are mostly lower than those produced for the gate with lip angle $\left(\theta=37^{\circ}\right)$.

The increase in flow rate leads to keep the $\left(\mathrm{K}_{\mathrm{b}}\right)$ for gate lip shapes $\left(\theta=37^{\circ}\right.$, and $\left.\theta=42^{\circ}\right)$ as positive and relatively high values as shown in Fig. 7. The figure has also indicted that for gate lip with $\left(\theta=35^{\circ}\right)$, the $\left(\mathrm{K}_{\mathrm{b}}\right)$ values are dropped to be negative up to gate opening $\left(\mathrm{Y} / \mathrm{Y}_{\mathrm{o}}=50 \%\right)$, after which, a significant increase in pressure coefficient values was observed accompanied with a gate opening increase for more than $50 \%$.

Figure 8 shows the variation of $\left(\mathrm{K}_{\mathrm{b}}\right)$ for the case of $\left(\mathrm{S}=0.25 \%, \mathrm{Q}_{\text {Low }}\right)$. It can be seen from this figure that the behaviour of $\left(\mathrm{K}_{\mathrm{b}}\right)$ is generally same for all considered gate

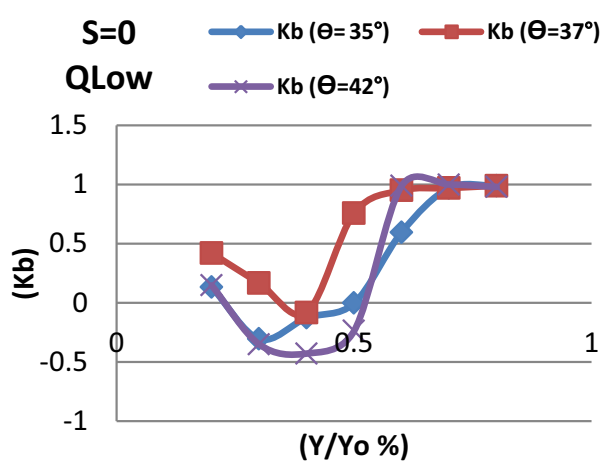

Fig. 5 Variation of bottom pressure coefficient with gate openings for different gate lips and $\left(Q_{\text {Low }} \& S=0\right)$ 


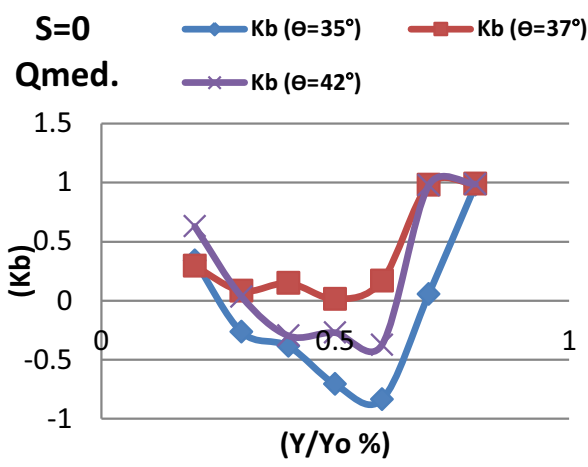

Fig. 6 Variation of bottom pressure coefficient with gate openings for different gate lips and $\left(\mathrm{Q}_{\mathrm{med}} \& \mathrm{~S}=0\right)$

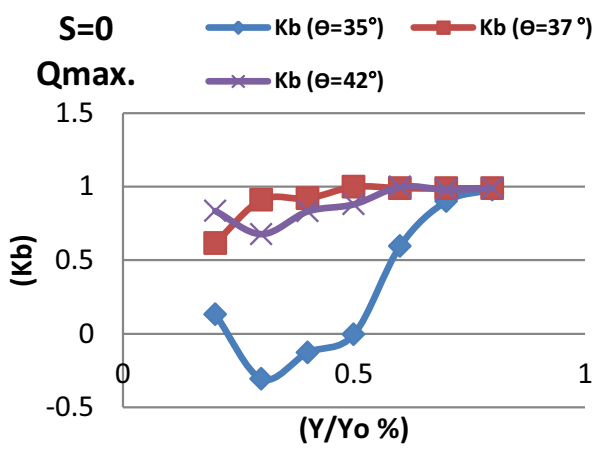

Fig. 7 Variation of bottom pressure coefficient with gate openings for different gate lips and $\left(Q_{\max } \& S=0\right)$

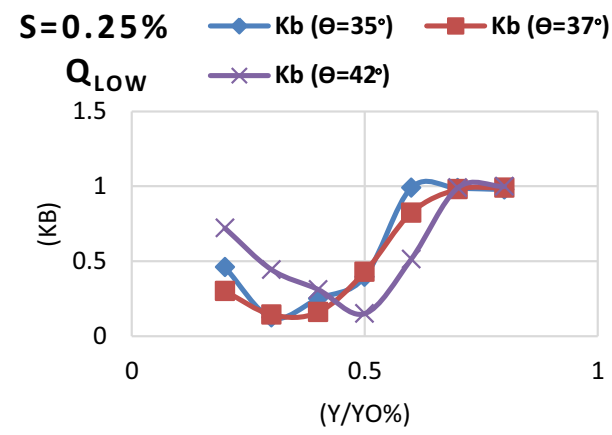

Fig. 8 Variation of bottom pressure coefficient with gate openings for different gate lips and $\left(\mathrm{Q}_{\text {Low }} \& \mathrm{~S}=0.25\right)$

shapes and significant values increase are occurred for gate opening ratios $\left(\mathrm{Y} / \mathrm{Y}_{\mathrm{o}} \geq 50 \%\right)$.

Figure 9 indicates that for gate lip shapes $\left(\theta=37^{\circ}\right.$ and $\left.\theta=42^{\circ}\right)$, the increase in flow rate led to increase the $\left(\mathrm{K}_{\mathrm{b}}\right)$ values uniformly with increase of gate openings. For gate lip shape with $\left(\theta=35^{\circ}\right)$, the $\left(K_{b}\right)$ values dropped to be negative up to gate opening $\left(\mathrm{Y} / \mathrm{Y}_{\mathrm{o}}=30 \%\right)$, beyond which, the values are increased and reach the maximum for gate opening $\left(\mathrm{Y} / \mathrm{Y}_{\mathrm{o}}=80 \%\right)$.
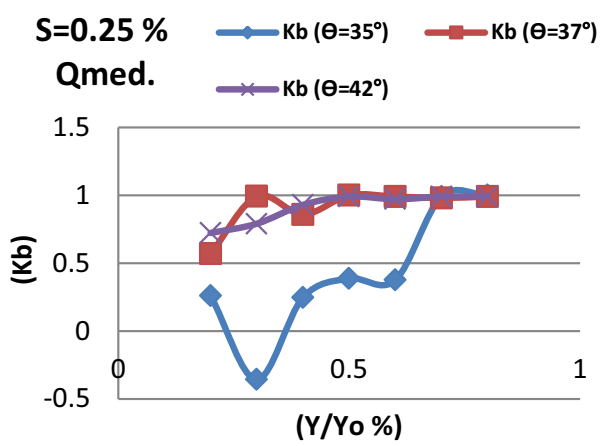

Fig. 9 Variation of bottom pressure coefficient with gate openings for different gate lips and $\left(\mathrm{Q}_{\text {med }} \& \mathrm{~S}=0.25 \%\right)$

The maximum flow rate caused an increase in the values of $\left(\mathrm{K}_{\mathrm{b}}\right)$ for gate lip with angle $\left(\theta=35^{\circ}\right)$, whereas its distribution profile keeps invariant to some extent. The other two considered gate lip shapes are not exposed to similar changes as shown in Fig. 10. The figure also indicates that increase in flow rate may not cause the $\left(\mathrm{K}_{\mathrm{b}}\right)$ values to be negative.

The effects of low flow rate and longitudinal slope of $(0.5 \%)$ are demonstrated in Fig. 11. It appears that increasing the slope has caused an increase in $\left(\mathrm{K}_{\mathrm{b}}\right)$ values of gate lip shape $\left(\theta=42^{\circ}\right)$, with uniform distribution along

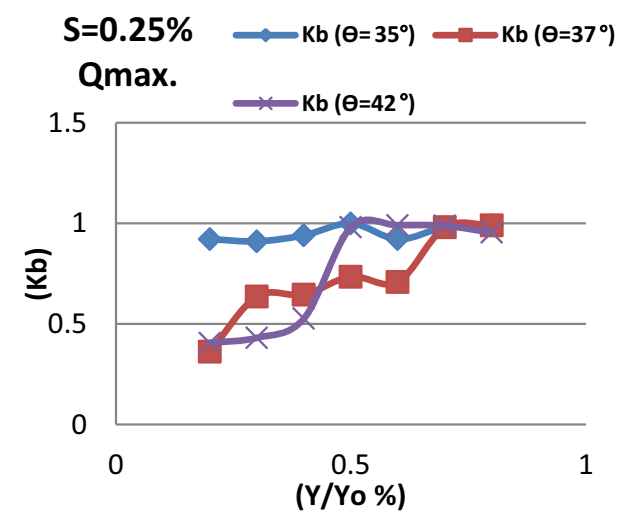

Fig. 10 Variation of bottom pressure coefficient with gate openings for different gate lips and $\left(\mathrm{Q}_{\max } \& \mathrm{~S}=0.25 \%\right)$

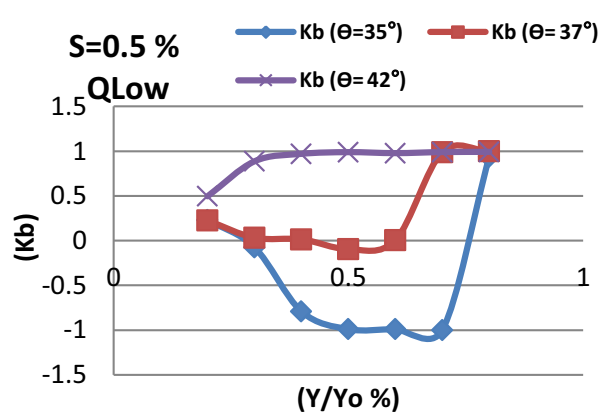

Fig. 11 Variation of bottom pressure coefficient with gate openings for different gate lips and $\left(\mathrm{Q}_{\text {Low }} \& \mathrm{~S}=0.5 \%\right)$ 

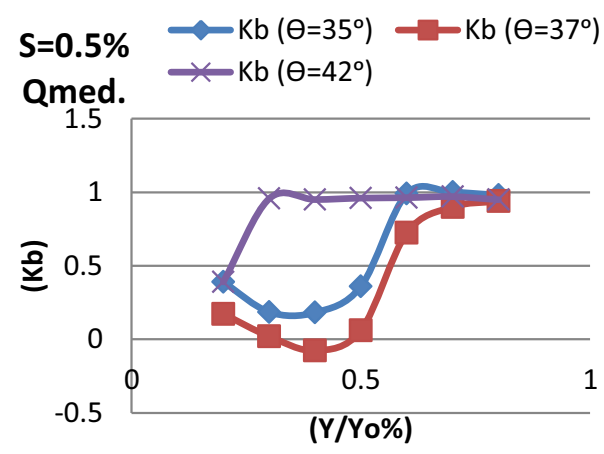

Fig. 12 Variation of bottom pressure coefficient with gate openings for different gate lips and $\left(\mathrm{Q}_{\text {med }} \& \mathrm{~S}=0.5 \%\right)$

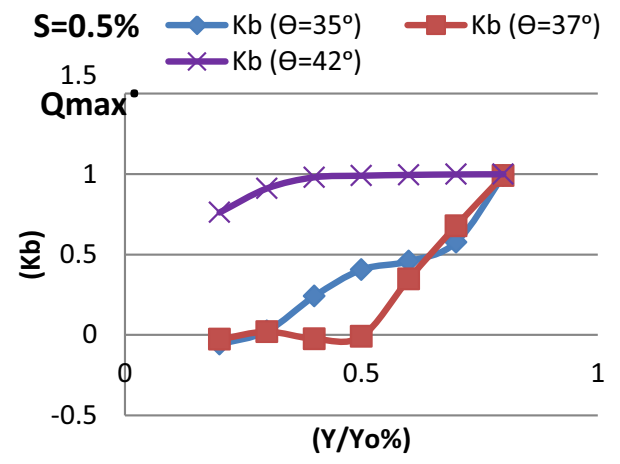

Fig. 13 Variation of bottom pressure coefficient with gate openings for different gate lips and $\left(\mathrm{Q}_{\max } \& \mathrm{~S}=0.5 \%\right)$

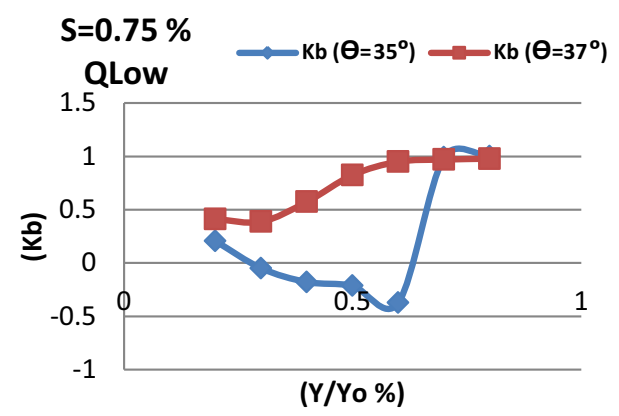

Fig. 14 Variation of bottom pressure coefficient with gate openings for different gate lips and $\left(\mathrm{Q}_{\text {med }} \& \mathrm{~S}=0.75 \%\right)$

most of gate openings. However, this case has led to a drop-in pressure values for other angles, especially the gate lip shape with $\left(\theta=42^{\circ}\right)$, which showed a decline toward negative values and hence the increase in downpull force it could be more probable. Overall, the bottom pressure coefficient values $\left(\mathrm{K}_{\mathrm{b}}\right)$ become high and positive for the case of large openings of the gate.

Figures 12 and 13 show that the increase in the flow rate values have led to an increase in the $\left(\mathrm{K}_{\mathrm{b}}\right)$ values for gate lip
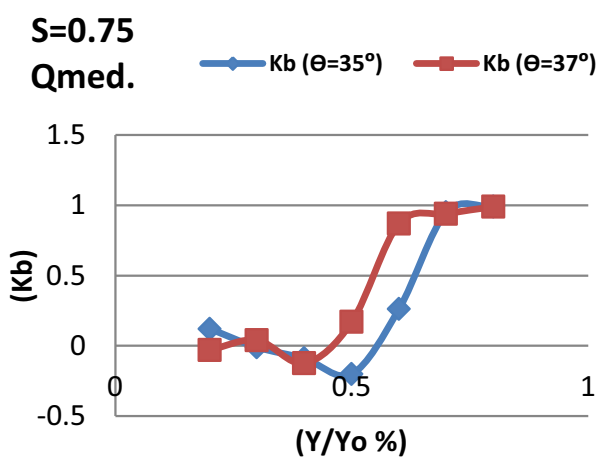

Fig. 15 Variation of bottom pressure coefficient with gate openings for different gate lips and $\left(\mathrm{Q}_{\text {med }} \& \mathrm{~S}=0.75 \%\right)$

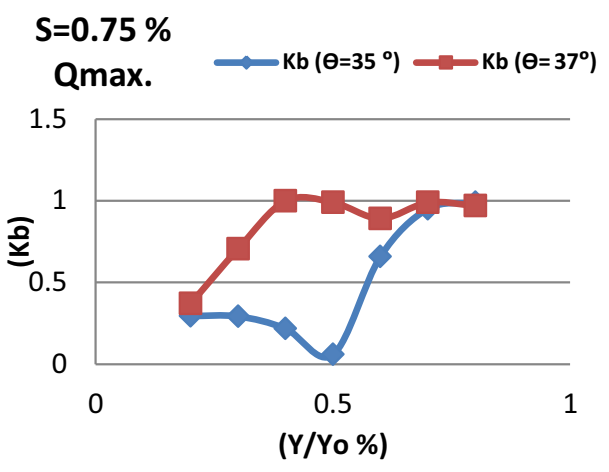

Fig. 16 Variation of bottom pressure coefficient with gate openings for different gate lips and $\left(\mathrm{Q}_{\max } \& \mathrm{~S}=0.75 \%\right)$

shapes $\left(\theta=35^{\circ}, \theta=37^{\circ}\right)$, while not significantly affect the values of $\left(K_{b}\right)$ for gate lip shape with $\left(\theta=42^{\circ}\right)$.

Figures 14,15 and 16 show the variation of $\left(K_{b}\right)$ for different flow rates when the longitudinal slope is increased to be $(0.75 \%)$. Mostly, the $\left(\mathrm{K}_{\mathrm{b}}\right)$ for gate lip shape with $\left(\theta=35^{\circ}\right)$,has little changes as the flow rate increases. A negative value is observed when flow rate is $\left(\mathrm{Q}_{\mathrm{med}}\right)$ and generally the smallest values are appeared when $\left(\mathrm{Y} / \mathrm{Y}_{\mathrm{o}}\right.$ $=50 \%$ ) for all flow rates.

The figures are also shown that for gate lip shape with $\left(\theta=37^{\circ}\right)$, and flow rates are $\left(\mathrm{Q}_{\text {low }}\right.$ and $\left.\mathrm{Q}_{\mathrm{med}}\right)$, the highest values of $\left(\mathrm{K}_{\mathrm{b}}\right)$ are obtained when the gate openings $\left(\mathrm{Y} / \mathrm{Y}_{\mathrm{o}}\right)$ exceed $50 \%$. The flow rate $\left(\mathrm{Q}_{\max }\right)$ seems to have caused the earlier creation of high $\left(\mathrm{K}_{\mathrm{b}}\right)$ values starting from $(\mathrm{Y} /$ $\left.\mathrm{Y}_{\mathrm{o}}=40 \%\right)$.

\section{Statistical Package of Social Sciences (SPSS) Analysis}

In order to analyse the results of measurements by using the principles of statistics, the Statistical package of social sciences (SPSS) is used to combine many parameters in a 


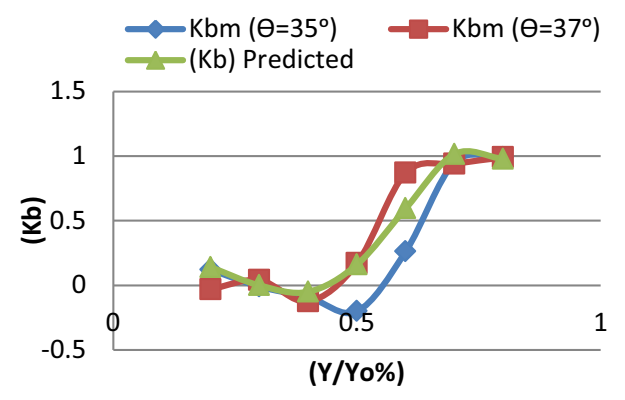

Fig. 17 Measured and predicted $\left(\mathrm{K}_{\mathrm{b}}\right)$ values for $\left[\left(\mathrm{Q}_{\text {med. }} \mathrm{S}=0.75 \%\right)\right.$ $\left(\theta=35^{\circ}\right.$, and $\left.\left.\theta=37^{\circ}\right)\right], \mathrm{R}^{2}=0.878$

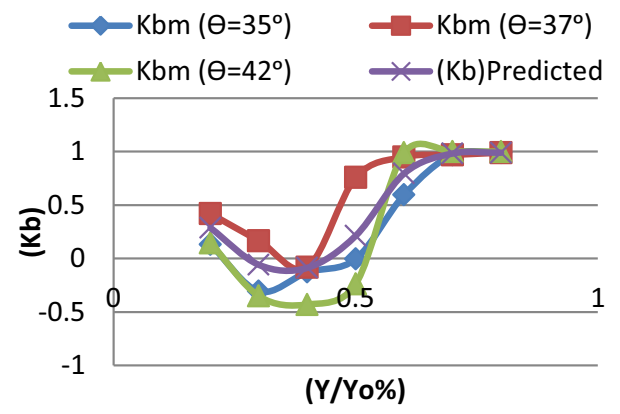

Fig. 18 Measured and predicted $\left(\mathrm{K}_{\mathrm{b}}\right)$ values for $[(\mathrm{QL} . \mathrm{S}=0)$ $\left(\theta=35^{\circ}, \theta=37^{\circ}, \theta=40^{\circ}\right.$ and $\left.\left.\theta=42^{\circ}\right)\right], \mathrm{R}^{2}=0.799$

suitable predictive function. Many functions are available, but the selection should be controlled by an acceptable value of correlation coefficient, which represents one of the best ways to get a good confidence for the applicability of function.

In present study the following form of sixth order polynomial function is selected in which the $\left(\mathrm{K}_{\mathrm{b}}\right)$ is considered as dependent variable and has been taken as function of gate lip angle $(\theta)$ and gate opening (Y):

$K_{b}=\left(A+B \cdot Y+C \cdot Y^{2}+D \cdot Y^{3}+E \cdot Y^{4}+\ldots+N \cdot Y^{n}\right)$

where A, B, etc. are constants obtained from the results of regression process of software.

Many cases of results were introduced to software to carry out the analysis of nonlinear regression for the data of different opening ratios $\left(\mathrm{Y} / \mathrm{Y}_{\mathrm{o}}\right)$ and angles $(\theta)$. The following results with often-good values of correlations are obtained.

The $\left(\mathrm{K}_{\mathrm{b}}\right)$ results of SPSS software analysis as predicted values $\left(\mathrm{K}_{\mathrm{b}} \mathrm{P}\right)$ are shown together with measured values $\left(\mathrm{K}_{\mathrm{b}} \mathrm{m}\right)$ in the Figures from 17, 18, 19 and 20 for selected cases. Figure 17 indicates the results of $\left(Q_{\text {med }} S=0.75 \%\right)$ for gate lip angles of $\left(\theta=35^{\circ}\right.$, and $\left.\theta=37^{\circ}\right)$. The form of

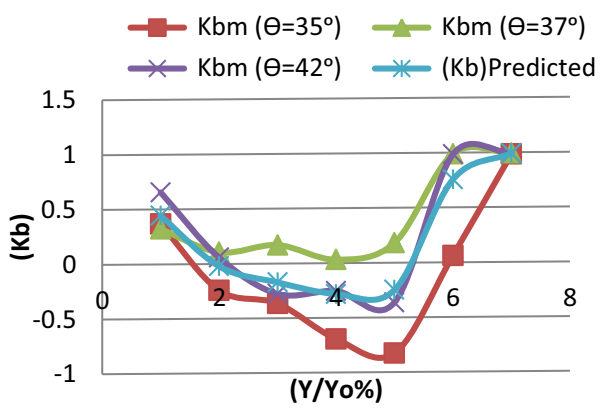

Fig. 19 Measured and predicted $\left(K_{b}\right)$ values for $\left[\left(Q_{\text {med }} S=0\right)\right.$ $\left(\theta=35^{\circ}, \theta=37^{\circ}\right.$ and $\left.\left.\theta=42^{\circ}\right)\right], \mathbf{R}^{2}=0.783$

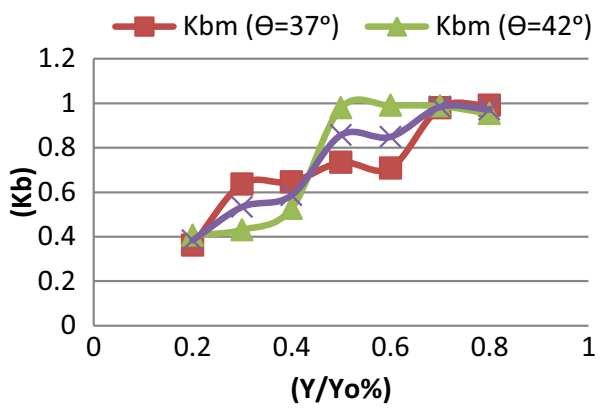

Fig. 20 Measured and predicted $\left(\mathrm{K}_{\mathrm{b}}\right)$ values for $\left[\left(\mathrm{Q}_{\max } \mathrm{S}=0.25 \%\right)\right.$ $\left(\theta=37^{\circ}\right.$ and $\left.\left.\theta=42^{\circ}\right)\right], \mathrm{R}^{2}=0.869$

Eq. (7) is used to determine the predicted values of $\left(\mathrm{K}_{\mathrm{b}}\right)$ for mentioned case.

$$
\begin{aligned}
K_{b}= & 46.99013-715.241 Y+4327.956 Y^{2}-13337.565 Y^{3} \\
& +22093.896 Y^{4}-18676.319 Y^{5}+6314.583 Y^{6} .
\end{aligned}
$$

The same process is repeated for all considered cases and Eqs. (8, 9, and 10) are applied to get the predicted values of $\left(\mathrm{K}_{\mathrm{b}}\right)$.The results are shown in the corresponding figures. It is obvious from all results that the correlation coefficients have been found with an acceptable limit for such experimental works. However, the functions, which were obtained as a result to the regression process, can be considered as applicable and useful to form perception with less effort about the $\left(\mathrm{K}_{\mathrm{b}}\right)$ values related to the selected conditions.

$$
\begin{aligned}
K_{b}= & 19.691-290.483 Y+1758.041 Y^{2}-5545.453 Y^{3} \\
& +9508.197 Y^{4}-8328.513 Y^{5}+2908.097 Y^{6} \\
K_{b}= & 22.369+388.617 Y-2586.650 Y^{2}+8621.792 Y^{3} \\
& -15370.968 Y^{4}+13969.088 Y^{5}-5065.467 Y^{6}
\end{aligned}
$$




$$
\begin{aligned}
K_{b}= & -39.573+596.955 Y-3522.554 Y^{2}+10566.195 Y^{3} \\
& -17043.619 Y^{4}+14085.757 Y^{5}+-4680.751 Y^{6} .
\end{aligned}
$$

\section{Conclusions}

The bottom pressure head coefficient was estimated based upon the results analysis of all sets of measurements. This pressure head coefficient is examined with effects of different gate lip angles, flow rates and longitudinal slopes. An attemp was used to analyze the results of bottom pressure coefficients $\left(\mathrm{K}_{\mathrm{b}}\right)$ by using the nonlinear regression of Statistical package of social sciences (SPSS).The comparison between the measured and predicted values of $\left(\mathrm{K}_{\mathrm{b}}\right)$ for specific cases were disccused.

Some of major conclusions are listed as follows:

1. For gate lip shape of $\left(\theta=35^{\circ}\right)$, the $\left(K_{b}\right)$ values are mostly being negative for a range of gate openings $(\mathrm{Y} /$ $\left.\mathrm{Y}_{\mathrm{o}}\right)$ around $50 \%$, except at the case of $\left(\mathrm{Q}_{\operatorname{med}}\right.$ and $\mathrm{Q}_{\max }$ For $\mathrm{S}=0.5 \%)$, the $\left(\mathrm{K}_{\mathrm{b}}\right)$ values are positive and increase with increasing the gate opening ratios.In general, for different flow rates and longitudinal slopes, the $\left(\mathrm{K}_{\mathrm{b}}\right)$ values are lower than those obtained from other gate lip shapes involved in current study.

2. For gate lip shape of $\left(\theta=37^{\circ}\right)$, The $\left(K_{b}\right)$ values are positive and varied uniformly from 0.5 to approximately zero near to $\left(\mathrm{Y} / \mathrm{Y}_{\mathrm{o}}=50 \%\right)$, then increased as gate openings increase. However, the considered $\left(\mathrm{Q}_{\max }\right)$ caused a general uniform trend of $\left(\mathrm{K}_{\mathrm{b}}\right)$ values and distribution along the all gate-opening ratios.

3. Regarding to the effects of varying flow rates on $\left(\left(\mathrm{K}_{\mathrm{b}}\right)\right.$ values and distribution of gate lip shape of $\left(\theta=42^{\circ}\right)$, it is noticed that these values are strongly related to the said variance. Moreover, even when the longitudinal slope is increased the $\left(\mathrm{K}_{\mathrm{b}}\right)$ values are also significantly increased. When longitudinal slope $(\mathrm{S})$ is $0.5 \%$, the higher values along with uniform distribution are kept obtained for $\left(\mathrm{K}_{\mathrm{b}}\right)$ for all gate openings ratios.

4. Fluctuations in $\left(\mathrm{K}_{\mathrm{b}}\right)$ values for all flow rates with slope $(\mathrm{S}=0.25 \%)$ were noticed to be embracing a general trend of increase with $\left(\mathrm{Y} / \mathrm{Y}_{\mathrm{o}}\right)$.

5. In general, the flow rates and slopes effects on the average values of bottom pressure coefficients could not be subjected to specific form.

6. Curves of $\left(\mathrm{K}_{\mathrm{b}}\right)$ versus $\left(\mathrm{Y} / \mathrm{Y}_{\mathrm{o}}\right)$ include in general a turning point (minimum value and may be negative) around $\left(\mathrm{Y} / \mathrm{Y}_{\mathrm{o}}\right)$ of $50 \%$, beyond which, the $\left(\mathrm{K}_{\mathrm{b}}\right)$ values rise to reach its maximum at $\left(\mathrm{Y} / \mathrm{Y}_{\mathrm{o}}\right)$ of $70 \%$ or more.

7. The results of SPSS software analysis show that all the correlation coefficients that have been found $(0.878$, $0.799,0.783$ and 0.869 ) are within the acceptable limits for such experimental works. However, the functions, which were obtained as a result to the regression process, can mostly be useful for the estimation of $\left(\mathrm{K}_{\mathrm{b}}\right)$ values for conditions compatible with those considered for this study. The results show that the range of variance with the experimental measurements was \pm $25 \%$. This is considered acceptable regarding the different conditions of testing.

\section{References}

1. T. M. Ahmed, Effect of gate lip shapes on the downpull force in tunnel gates experimental study of pressure coefficient along inclined bottom surface of dam tunnel gate, Ph.D. Thesis submitted to the College of Engineering, University of Baghdad, 1999

2. T.M. Ahmed, Experimental study of pressure coefficient along inclined bottom surface of dam tunnel gate. Eurasian J. Sci. Eng. 1(2), 52-53 (2016)

3. T. M. Ahmed, A.O. Anwar, Effects of gate geometries on top pressure coefficient of dam tunnel gate, in IEC 2016 Conference Proceeding, pp. 85-90

4. B.T. AL-Kadi, Numerical evaluation of downpull force in tunnel gates, Ph.D. Thesis submitted to the College of Engineering, University of Baghdad, 1997

5. R.M. Almaini, M.T. Al-Kifae, S.A.M. Alhashimi, Prediction downpull force on tunnel gate with different gate lip geometry. J. Kerbala Univ. 8(4), 9 (2010)

6. I. Aydin, I. Telci, O. Dundar, Prediction of downpull on closing high head gates. J. Hydraul. Res. 44(6), 822-831 (2006)

7. V.P. Bhargava, S. Narasimhan, Pressure fluctuations on gates. J. Hydraul. Res. 27(2), 215-231 (1989)

8. G. Cox Robert, B.P. Ellis, W.P. Simmons, Hydraulic downpull on high head gates, in ASCE Discussion Hy. 5 (1960)

9. R. A. Elder, J.M.Garrison "Flow induced hydraulic forces on three leaf intake gates, in ASCE, vol. 90(3), IAHR/AIRH Hydraulic Report, Balkema, Rotterdam, 2001, pp 215-233

10. A. Khosrojerdi, Hydraulic studies of pressure distribution around vertical lift gates. Indian J. Sci. Technol. 5(3), 2268-2272 (2012)

11. J. Markovic-Brankovic, H. Drobier, New high head leaf gate form with smooth upstream face. Tem J. 3, 19 (2013)

12. E. Naudaschers, H. Kobus, R.P.R. Rao, Hydrodynamic analysis for high head leaf gates, ASCE, vol. 90(3) (1964)

13. M.N. Naderi, E. Hadipour, numerical simulation of flow in bottom outlet of narmashir dam for calculating of hydrodynamic forces. Bull. Env. Pharmacol. Life Sci 2(11), 87-93 (2013)

14. B.T.A. Sagar, "Downpull in High-head Gate Installations, Part 1. Water Power Dam Construct 3, 38-39 (1977)

15. B.T.A. Sagar, "Downpull in High-head Gate Installations, Part 2. Water Power Dam Construct. 4, 52-55 (1977)

16. B.T.A. Sagar, "Downpull in High-head Gate Installations, Part 3. Water Power Dam Construct. 5, 29-35 (1977)

17. T.M. Taher, A.O. Anwa, Effects of gate lip orientation on bottom pressure coefficient of dam tunnel gate. Arab. J. Sci. Eng. (2016). https://doi.org/10.1007/s13369-016-2202-7

18. N.D. Thang, Gate vibrations due to unstable flow separation. J. Hydraul. Eng. 116(3), 342-361 (1990)

19. Uysal, mehmet akiş. Prediction of downpull on high head gates using computational fluid dynamics. Diss. Middle east technical university, 2014 